\title{
Review of Research in Feature-Based Design
}

\author{
O.W. Salomons, F.J.A.M. van Houten, and H.J.J. Kals, University of Twente, Enschede, The \\ Netherlands.
}

\begin{abstract}
Research in feature-based design is reviewed. Feature-based design is regarded as a key factor towards CAD/CAPP integration from a process planning point of view. From a design point of view, featurebased design offers possibilities for supporting the design process better than current CAD systems do. The evolution of feature definitions is briefly discussed. Features and their role in the design process and as representatives of design-objects and design-object knowledge are discussed. The main research issues related to feature-based design are outlined. These are: feature representation, features and tolerances, feature validation, multiple viewpoints towards features, features and standardization, and features and languages. An overview of some academic featurebased design systems is provided. Future research issues in feature-based design are outlined. The conclusion is that feature-based design is still in its infancy, and that more research is needed for a better support of the design process and better integration with manufacturing, although major advances have already been made.
\end{abstract}

Keywords: Features, Form Features, Design Features, Manufacturing Features, Design by Features, Feature-Based Design, Feature-Based Process Planning, Multiple Views on Features, Feature Representation, Feature Validation, Tolerances, Standardization, Languages, Intelligent CAD, Object Orientation, Feature Taxonomies, CAD/CAPP Integration, Design Process

\section{Introduction}

Features can be viewed as information sets that refer to aspects of form or other attributes of a part, such that these sets can be used in reasoning about the design, performance or manufacture of the part or assemblies they constitute. Feature technology, therefore, is expected to be able to provide for a better approach to integrate design and applications following design such as engineering analysis, process planning, machining, and inspection.

Currently three main views are discerned on how to obtain application features such as manufacturing features, analysis-and-inspection features from a product model: ${ }^{1-3}$

\section{Feature recognition.}

In this approach application features are automatically or interactively recognized from a model of the object under consideration. Product models from both conventional solid modelers and featurebased modelers can be subjected to feature recognition. Good reviews on feature recognition are found in References 1 and 2.

\section{Design by features.}

A product model can be built by using (design) features; this is known as design-by-features or feature-based modeling. Features are functional elements to designers. Design features often differ from application features however.

\section{Interactive feature definition.}

In this approach features are defined by human assistance or interactively.

At the moment the first two views prevail. In Reference 4 the belief is advocated that feature recognition and feature-based design alone are not sufficient to fulfill the requirements of CAD/CAPP integration. It is presently believed that future CAD/CAPP systems should provide for both feature recognition and design-by-features. ${ }^{3,5,6,7}$ In Reference 8 it is even advocated that all three approaches should be integrated in a unified approach; a first attempt of this has been implemented within the ASU Features Testbed (see section 6.1). 
In comparison with the other two approaches, feature-based design has the advantage of storing relevant information for applications during the design process, as well as offering the possibility for considering manufacturing and assembly concerns early in the design process. Using featurerecognition or interactive feature definition alone, this would not have been possible. Thus featurebased design is a promising means of achieving better CAD/CAPP integration.

Recently, a vast number of papers and other publications on feature technology-especially focusing on feature-based design - have come forward. This paper attempts to provide a stateof-the-art review of research in feature-based design with a focus on CAD/CAPP integration, and aimed at researchers both in in the design area and in the process- planning area. It should be noted, however, that a review paper like this cannot be complete nor replace the original papers. In the remainder of this section we will briefly discuss the potential benefits and drawbacks of feature-based design as seen from the process-planning pointof-view and from the design point-of-view. Finally we will give an outline of the rest of this paper.

\subsection{Process-Planning Point-of-View}

Process planning deals with selecting and defining the processes that have to be performed to transform raw material into a given shape; for surveys refer to References 9,10 or 11 . The decisions made in process-planning relate to single parts. Process planning includes: interpretation of the product model, selection of machine tools, selection of tool sets, selection of setups, selection of machining operations and their sequence, selection of cutting tools, design of jigs and fixtures, calculation of cutting conditions, determination of tool paths, NC part-program generation and capacity-planning. ${ }^{3}$

The first use of features has been reported in computer-aided process planning. In computeraided process planning, it is necessary to analyze the part under consideration to generate a detailed process plan. In this analysis of the component, (manufacturing) features are the key to generate the process plan. There are two reasons for this: ${ }^{12}$ manufacturing features provide for a natural form of communication; process planners think in terms of holes, pockets etc., and manufacturing features simplify process planning since there are only a finite number of ways to manufacture a feature.

Automation of process planning requires that product data be extractable from the product model automatically. However, CAD product representations in product-modelers usually differ from the type of information required in CAPP (e.g. manufacturing features). Until now, feature recognition has been the most common approach to extract manufacturing features from CAD product models. In fact, this means inferring a lot of information from the CAD product model at high cost while this information already has been generated during the design process. This information has been lost when the result of the design process was stored in the CAD model. Feature-based design could (at least partly) help to overcome this problem.

\subsection{Design Point-of-View}

The decisions that are usually made in design are not limited to single parts only; the decisions also relate to assemblies. The first references on features in mechanical engineering design, ${ }^{13-15}$ were concerned with modeling only single parts however. This is probably be due to the features concept being brought over from process-planning where the decisions are indeed related to single parts. Although feature-based modeling of single parts was a significant improvement when compared with traditional CAD systems, true computer aid of designers still had not been achieved. As we will show later, this situation is now changing.

From a design point-of-view, feature-based design has the potential of supporting the design process better than current CAD systems do. Features are meaningful elements to designers and can speed up the design process as well as provide a means for standardization, thus reducing cost and time-to-market. Also, improving the quality of the design and improving the link between design and applications such as process-planning-and-analysis are expected advantages of feature-based design.

Despite the promises of feature-based design as mentioned above, feature -based design has not yet reached its expectations. The main reasons for this, according to Reference 8 , are that there is no finite 
set of features in design; data management problems are non-trivial; the need for feature-recognition does not go away as features are application-specific; and it is not clear whether designers actually design in terms of features or that features result from other considerations.

\subsection{Organization}

We have chosen to place research in featurebased design in a somewhat wider perspective by trying to indicate its place within the broader context of research in engineering design. We will try to indicate those parts of research in engineering design that are closely related to research in featurebased design or that might become important for research in future feature-based design. We have, therefore, chosen to separate the following items: feature definitions (section 2); features and the design process (section 3); features and the designobject and design knowledge (section 4); research issues (section 5); academic feature-based design systems (section 6); and conclusions (section 7).

Section 2 will discuss feature definitions as feature definitions have been and still are subject to change, which can cause a lot of confusion. In sections 3 and 4 , features are related to the design process, the design-object, and the design knowledge which is a classification based on recent engineering design literature. ${ }^{\mathbf{1 6 - 1 8}}$ Section 5 indicates the main research issues related to featurebased design. Section 6 will discuss a few academic feature-based design systems. Finally, in section 7 , future research will be indicated and conclusions will be drawn.

\section{Feature Definitions}

When speaking about features, usually formfeatures are meant. The first definitions of formfeatures were process-planning-oriented like the following definition of a workpiece feature: a specific geometric configuration formed on the surface, edge or corner of a workpiece. ${ }^{19}$

A more recent definition of a process-planning related form-feature is a distinctive or characteristic part of a workpiece, defining a geometrical shape, which is either specific for a machining process or can be used for fixturing and/or measuring purposes. $^{20}$

Another more recent definition, also applicable to domains other than just process planning, is the definition of a form-feature by Wingard: a generic shape that carries some engineering meaning. ${ }^{6}$

A lot of confusion has arisen about feature definitions as features became also relevant to other application domains such as engineering design and analysis, and because features did not necessarily relate to form. Therefore, we will consider the first two above-mentioned definitions as definitions of manufacturing form features, or simply, manufacturing features and not as features in general. The reason for this is twofold: first, to indicate that the features are form-features and not more-or-less abstract features; second, because the features are related to manufacturing processes; they only have meaning for manufacturing, and not necessarily for other applications.

As feature technology spread from processplanning towards design, inspection and engineering analysis, feature definitions tended to become more general. Examples of these more general definitions of features are:

- Recurring patterns of information related to a part description. ${ }^{2}$

- A semantic grouping used to describe a part and its assembly. It groups in a relevant manner functional, design and manufacturing information. $^{21}$

- A geometric form or entity whose presence or dimensions are required to perform at least one CIM function and whose availability as a primitive permits the design process to occur. ${ }^{15}$

- A carrier of product information that may aid design or communication between design and manufacturing, or between other engineering tasks. ${ }^{22}$

- Any entity used in reasoning of design, engineering and manufacturing. 5

- A region of interest. ${ }^{5}$

A lot of different kinds of features have been proposed: functional features e.g., ${ }^{\mathbf{2 1 , 2 3}}$ assembly features, ${ }^{24}$ mating features, physical features ${ }^{25}$ and even abstract features. ${ }^{26}$ Abstract features can be used during the design process, as a lot of features will not be known in detail before the end of the 
process. The definition of an abstract feature is as follows: Entities that cannot be evaluated or physically realized until all variables have been specified or derived from the model. ${ }^{26}$

No matter how general the definition of the term feature, what seems to be taken for granted is that features finally are attached to some geometric shape. Shah defines the least requirements a feature should fulfill: ${ }^{22}$ a physical constituent of a part, be mappable to a generic shape, have engineering significance, and have predictable properties.

\section{Features and the Design Process}

This section consists of 4 subsections. In the first three subsections some general concepts of the design process important to feature-based design will be explored. These issues are (in a nutshell): the mechanical engineering design process (section 3.1 ), models of the design process (section 3.2) and the role of function in the design process (section 3.3). Based on this broader context of the design process in general, feature-based design processes are explored in section 3.4.

\subsection{The Mechanical Engineering Design Process}

The mechanical engineering design process is a complex and not yet well understood cognitive process conducted by humans. As the solution space is usually extremely large, a designer will have to follow a certain strategy or method to successfully finish the design process. The design process has been analyzed by several researchers. Reviews of recent research in engineering design in general can be found in References 16, 17 and 27. Some aspects that are of relevance to feature-based design and which have been treated in more detail in these papers will be discussed in the following sections.

\subsection{Models of the Mechanical Engineering Design Process}

Feature-based design systems can be based on a model of the design process. The following sub sections will, therefore, discuss some models of the design process. As in the Finger and Dixon review, ${ }^{16}$ we will distinguish prescriptive, descriptive and computer-based models of the design process.

\subsubsection{Prescriptive Models of the Design Process}

Methodic prescriptive models of the design process have been proposed, especially by German authors. Examples of these are Rodenacker, ${ }^{28}$ Pahl and Beitz, ${ }^{29}$ Koller, ${ }^{30}$ Roth, ${ }^{31}$ and the guidelines of the German Association of Engineers, VDI 2221. ${ }^{32}$ In Reference 16, a more detailed review focused on primarily American efforts is given. The prescriptive approaches distinguish different phases and actions to be carried out in each phase in the ideal case of a top-down design process. Examples of design phases that are often referred to are the conceptual, structural, and detail or parametric design phases. Prescriptive approaches in which features are used have seldom been reported; one example, however, is the work by Bauert. ${ }^{33-37}$

\subsubsection{Descriptive Models of the Design Process}

From studies of practicing designers it became apparent that designers do not follow prescriptive models very well in practice; they often skip phases or actions in phases; they constantly switch from conceptual design actions to more detailed design actions or phases and vice versa. One of these studies of designers can be found in Reference 38, which also gives an empirical or descriptive model of the design process derived from (protocol) studies of individual designers. Descriptive studies have also shown that designers sketch a lot. Therefore, in Reference 39 a system that allows a computer to capture sketches has been described. The system recognizes design features and builds a solid feature-based model from this. Refer to Reference 16 for more details on descriptive models in general. Protocol studies in which design features played a role are References 40-42. In Reference 40 the fundamental geometric attributes or features of design were studied by having designers interpret drawings. In Reference 41 the information requests of mechanical engineers were studied in general; information requests on features were also included. 
In Reference 42 the development and propagation of constraints and features in the mechanical engineering design process was studied.

\subsubsection{Computer-Based Models of the Design Process}

Finger and Dixon discern computer-based models of the design process for three classes of design problems: parametric design, configuration design or structure design, and conceptual or preliminary design. ${ }^{\mathbf{1 6}}$ As we will see in the following sections, research in feature-based design so far can be placed within the computer-based approach. Moreover, feature-based design till recently has primarily been involved with parametric design but is now evolving towards configuration and conceptual design. In Reference 43 the general mismatch between contemporary CAD/CAM/CAE software and engineering tasks has been described. Feature-based design could help overcome some of these drawbacks.

First examples of research in which different views on the processes have been combined are found in References 34 and 35, combining a prescriptive and a computer view, and References 44 and 39 , combining descriptive and computer views. It is the authors' belief that as feature-based design heads towards assisting larger portions of the design process, besides having a computer view, research with prescriptive and descriptive views towards the design process is important to take into account as well.

\subsection{The Role of Function in the Design Process}

Function will be regarded as what a design-object is supposed to do: its intended behavior. Designers generally think in functions before they are concerned with geometry. Functions can exist at different levels of abstraction, according to the design phase that one is in. In preliminary design phases, functions usually are independent of working principle, whereas, in later design phases, when functions have been detailed out, functions become more and more dependent on the working principle that has been chosen. In the following, a distinction between three levels of functions will be made.

- General functions: This term has been taken from Roth. ${ }^{31}$ These functions are restricted in number, act on matter, energy or information and are independent of working principle.
- Specialized functions: This term has also been taken from Roth. ${ }^{31}$ These functions are not restricted in number, and act on forces, moments, etc. They are still independent of working principle; in catalogs, per specialized function, working principles can be found.

- Working principle-dependent functions. This category has been added by the authors. These functions are inherent to the working principle chosen; they are performed by the components of the assembly. Often, even the working principledependent functions can be decomposed into sub-functions.

A lot of research has been done investigating the role of function in the design process, particularly to computer-assist the designer in the more conceptual levels of the design process, i.e., focusing on the first 2 categories of functions. Examples of this kind of research are in References 29, 30, 31, 45; and more recently, References 46-48 using functions of categories 1 and 2 . These functions belong to the more preliminary design phases in which features so far have not shown to be of great use.

From a features point-of-view, the third function category is most interesting, as features are related to a component (part). Working principledependent functions usually materialize in the features that form the interface with other components. There is not an extensive set of working principledependent or low-level functions at component and feature levels. In References 49 and 50, a functional modeler is proposed and a list of component and feature-related functions is identified from practice. These are (from component towards feature level): contain, convey, convert, control, house, support, locate, drive, guide, limit, seal, fasten, lubricate, strengthen and conform to.

\subsection{Feature-Based Design Processes}

The distinction between using features in parametric design tasks only and in other design tasks such as conceptual and structure design as well corresponds to the distinction made by von Rimscha: ${ }^{51}$ the a priori approach and the a posteriori approach towards feature-based design. These two approaches will be discussed in sections 3.4.1 and 3.4.2 respectively. Section 3.4 .3 will discuss the role of features in "design for $\mathrm{X}$ " processes. 


\subsubsection{A Priori Approach Towards Feature-Based Design}

The $a$ priori approach towards design by features starts with more abstract notions to be gradually enriched by geometric and other detailed information. Thus, the a priori approach towards featurebased design satisfies the needs of more tasks of the design process than just (part of) the detailed design tasks. The terms abstract features, mating features, functional features and assembly features as mentioned in section 2 are introduced in this approach; except for geometry and topology, assemblies and functions could be modeled using these features.

The notion of design-by-least-commitment as proposed by Mäntylä $\mathbf{5 2}$ could be encapsulated within the a priori approach. Design-byleast-commitment means that if the exact shape of a part is functionally not important, the designer should not make an arbitrary choice but leave it unspecified.

\section{Features in Conceptual Design}

In conceptual design, high-level general or specialized functions of the product to be designed are determined as well as the principle solutions or physical embodiments for fulfilling these functions. High-level functions are addressed in References 46 and 53 as part of the DICAD system and in the KALEIT system.$^{36-37}$ However, high-level functions are generally not related to features as most of the components that the design-object consists of are not known in the stage of modeling the high-level functions.

In References 54 and 25 the notion of a physical feature has been introduced. After the "design with features" approach as proposed by Dixon et al ${ }^{55}$ for detail design, Kiriyama et al, recently proposed to use "design with physical features" in conceptual design tasks. Physical features can be regarded as the principle solutions. Not much research has been done on this approach towards design-by-features.

\section{Features in Configuration Design}

In configuration or structure design, a physical concept is transformed into a configuration with a defined set of attributes, but with no particular values assigned. ${ }^{16}$ The use of features in the configuration-design phases is relatively new.
Structural design in more general terms has been addressed in Reference 56. In Reference 57 automated design of non-standard extruded shapes using features has been described. In Reference 58 it has been proposed to use features for structural design.

In Reference 44, there is a general description of a design-object's form and function based on empirical data obtained from a descriptive view towards the design process (protocol studies).

In Reference 59 it is advocated that except for the form of features, also their function should be represented. However, the relation between form and function is not well understood.

In assembly-modeling, a lot of papers have been published recently; an overview of the stateof-the-art in assembly modeling with computers up until 1988 is found in Reference 27. The Finger and Dixon review ${ }^{16}$ gives a more recent survey. In References 60-61, initial work on representing assemblies has been done. Currently, the central issue is of representing assemblies, i.e., geometry and spatial relations among components. In the following, we will review the more recent attempts towards assembly modeling using features that were not covered by the survey papers mentioned above.

An example of a more recent paper is by Kimura et $\mathrm{al}^{\mathbf{6 2}}$ proposing the notion of context which represents a machine structure from a functional point-of-view independent of part structure. In Reference 63 , a system is proposed in which the designer has access to standard component interface geometry. In Reference 64, the main concern is given to the description of contact surfaces.

In Reference 65 it has been proposed to use graphs for representing assemblies; components are nodes in the graph, and arcs represent mating relations between features. Similar approaches using spatial relations between components are reported in References 66-68. In Reference 69 the representation of assemblies is considered with respect to automatic tolerance-chain-generation. Ko et $\mathrm{al}^{\mathbf{7 0}}$ proposed four mating conditions: against, fits, tight-fits, contact. A lot of references report similar ideas, e.g. ${ }^{67}$

Assembly representation of Helsinki University of Technology Assembly Design System HUTADS $^{\mathbf{7 1}}$ has been based on the theory presented in Reference 60 . The design of joints with HUTADS has been described in Reference 72 . 
In Reference 24, the concept and use of features is extended to provide a functionality-driven modeling capacity that allows for the representation of both tolerance and assembly information. In Reference 51, a unified approach towards feature modeling and assembly modeling is proposed. In Reference 73 assemblies can be modeled by relating nodes serving as geometric points whose positions and relative dependencies define components and features. Giacometti et al, ${ }^{\mathbf{2 1 , 2 3 , 7 4}}$ support the topdown design of mechanical assemblies with 'functional features.' Geometry is limited to the description of functional volumes and surfaces and is encapsulated in volumic features.

Support of designers with standards and standard components such as bearings as well as decision tables and formulas in conjunction with features has recently been advocated by Bauert. ${ }^{36}$ Bauert's system will be detailed more thoroughly in section 6 .

\subsubsection{A Posteriori Approach Towards Feature-Based Design}

The a posteriori approach-until now the most usual approach towards feature-based design-is related only to detail-design tasks. In these tasks, so-called form features, material features and primitive features or precision features have been used to model single parts. These features are used to define the nominal shape of a component, its material properties, and its variational geometry. The $a$ posteriori approach can be seen as a parametric design approach.

In detailed design phases, the nominal form, variational form (tolerances), and material information of a part are documented. The documentation of these results can be achieved using the a posteriori approach towards design-by-features. Good reviews of design-by-features in the $a$ posteriori approach are found in References 2, 6, 75, 76, 77, and 78 . In the a posteriori approach, one works with features that have a pre-defined form, form features, to arrive at the nominal shape of components. The form feature concept is widely used; often one speaks about features when actually form features are meant. Shah introduced the terms of material and precision features for the documentation of materials and tolerances. ${ }^{\mathbf{7 9 , 8 0}}$ In the following we will therefore discuss form, material, and precision features.

\section{Form Features}

Form features are intended to achieve a given function or to modify the appearance of a part. ${ }^{69,81}$ Wang defines a form feature as specific configurations on surfaces, edges, or corners of a part such as holes, slots etc. In the following we will adopt the definition of a form feature by Wingard. ${ }^{6}$ (See section 2).

The form-feature concept requires the association of engineering significance with shape. The disadvantage of this approach is that although design intent is captured better than in conventional solid modelers (design features usually have some engineering significance) design intent is hard to recover because engineering significance is often implicit to a feature. How form features could be represented will be discussed in section 5.1.

The first form-feature-based modeling systems allowed only a fixed set of form feature templates, which were not user-extendible. Later, pre-defined taxonomies of feature classes were suggested, extendible only with new form-feature classes falling into previous categories. Later systems have in some cases allowed a pre-defined set of classes to be more freely extendible, e.g., see Reference 82 .

In the a posteriori approach one could model with pre-defined manufacturing form-features, or with specific pre-defined design form-features. The latter option is usually preferred by the designer. One usually starts either with a more-or-less complete geometrical model and defines form features on it, or one starts from scratch by combining form features from a standard library. Designing with pre-defined form features can reduce the number of input commands. This is especially advantageous in redesign. The parametric representation of features provides a powerful way to change features with respect to their dimensions.

Dixon et al, have developed a number of formfeature-based applications: manufacturability evaluation of castings, ${ }^{83}$ design of injection moulds ${ }^{84}$ and extrusion designs. ${ }^{57}$ Features were applicationspecific and no solid modeling functions were supported. For more general papers by Dixon et al, refer to References 55 and 85 . See Table I in section 5 for some more details on the research in featurebased design by Dixon et al.

One of the most interesting developments in the $a$ posteriori approach is that of the Arizona State 
University ASU Features Testbed. In section 6.1 we will review the ASU Features Testbed in some more detail.

\section{Material Features}

In Reference 79 material features have been introduced for the ASU Features Testbed. Refer to section 6.1 for more details.

\section{Precision Features}

Shah et al, were the first to introduce precision features for use in the ASU Features Testbed. ${ }^{\mathbf{8 0}}$ Wang et al, discern the very similar notion of what they call primitive features in References 69 , and 81. A primitive feature is a basic geometric entity of a part such as surfaces, edges and vertices, or auxiliary geometric attributes of a part such as center lines and center planes. Form features are built on top of primitive features. Primitive features are referred to in defining dimensions and tolerances, and in specifying mating features in the assembly description.

\subsubsection{Features and Design for $X$}

Recently one has become aware of the necessity of considering not only the function, fit, and form of a design-object but also manufacturability, assembleability, serviceability and even the complete lifecycle of a design-object. In this respect, one speaks of design for manufacture (DFM), design for assembly (DFA), or more, in general, of design for $X$ or concurrent design or concurrent engineering. Features also can assist in these more specific design processes. Examples of relevant references are found in References 78, and 86-93. Some of these will now be reviewed:

Wierda has been concerned with cost information feedback for designers in feature-based modeling. ${ }^{78}$ Cutkosky and Tenenbaum ${ }^{86}$ describe First-cut, a system in which designs are developed step-by-step along with plans for manufacturing them. Refer to Table I (section 5) for more details on this approach. It is expected that the traditional process-planning task will change as feature-based modeling with manufacturability evaluation for both complete and incomplete parts comes about. ${ }^{89}$

In manufacturability evaluation, Ranta et al, ${ }^{90}$ discern two classes of problems: feature attribute problems (e.g., critical tolerances within a feature) and inter-feature problems (e.g., feature interactions and dimensions between form-features).

\section{Features and the Design-Object and Design Knowledge}

Sections 4.1 and 4.2 will consider the designobject and the design knowledge respectively. Section 4.3 explores the relation between the designobject, design knowledge and features.

\subsection{The Design-Object}

In many references, design-objects are considered as individual components or parts, although in practice, designers must consider an assembly rather than individual components. The designobject or model is the result of the design process. Except for geometry, the design-object also has to contain information on dimensions, tolerances, material etc. Many people argue that the designobject should also contain design intent or engineering significance. This could be the function of the design-object, constraints posed on it, or the manufacturing methods by which it should be made.

Different viewpoints could exist towards the same design-object. ${ }^{27}$ Meta models have been proposed from which application dependent models can be inferred. One example of this is the IIICAD system; ${ }^{94}$ see also section 6.2 .

If one is willing to computer-support more phases of the design process than current CAD systems do, the product model should include the results of the diverse phases. For instance function, structure and geometry should be part of the product model. Some of the first attempts towards such an integrated product model are the DICAD system ${ }^{\mathbf{5 3}}$ and GEKO. ${ }^{36-37}$ Another attempt is described by Giacometti in Reference 21. Refer to section 6 for more details.

Although information beyond just geometric information should be available in design-object models, geometric information is still the core of the information in the product model. Solid modeling is the only way for an unambiguous geometric representation of 3-D objects. For a survey on solid modeling refer to Reference 95 . The most wellknown solid-modeling geometric representations are boundary representation (B-rep) and construc- 
tive solid geometry (CSG). Recently, non-manifold modeling has been proposed. ${ }^{96-97}$ Form-features are usually represented geometrically by one of the above representations: for more details on formfeature representation, refer to section 5.1. Other information such as tolerance and material (feature) information usually can be attached easily to the geometric data structure of a product model.

\subsection{The Design Knowledge}

Both design-process knowledge and designobject knowledge are required if one intends to computer-support the design process. The application of expert systems and artificial intelligence (AI) in future CAD systems seems partially able to meet this requirement. In References 98 and 99, the results of a literature research into the application of AI in methodic design has been presented. Design knowledge representation and knowledge acquisition are central issues here. According to Reference 98 there are three ways of representing design knowledge:

Logic-Logic is expressed in a formal notation by which it is possible to infer inference rules and reason with the knowledge.

Rules-In a rule-based system, knowledge is represented in so-called production rules: IF.....THEN....

Structured forms-Logic and rules usually can be used only for representing simple facts. Complex structures occur in daily life however; in reality there are objects with characteristics and relations etc. These objects and relations can be taken as the basis of knowledge representation. Examples are: frames, scripts, semantic networks and conceptual dependency.

More detailed information on the above subjects can be found in References 36, 37, and 46. Design knowledge first has to be acquired before it can be represented. Knowledge sources can be literature or experts. There is a diversity of knowledge acquisition methods.

\subsection{Features and the Design-Object and Design-Object Knowledge}

From the definitions in section 2, it can be inferred that features can be used to describe the design-object as well as to capture design-object knowledge. Features provide a means to represent objects both symbolically and geometrically. How features should describe the design-object is still a subject of research, and will be discussed later in section 5.1, feature representations. In capturing design-object knowledge, feature hierarchies or taxonomies have been proposed. Object-oriented software and databases seem to be able to support the feature concept as well as the feature taxonomy idea. Therefore, the next sections will explore feature taxonomies (section 4.3.1) as well as object orientation (section 4.3.2).

\subsubsection{Feature Taxonomies}

A major advantage of a feature taxonomy is the structured way in which it can be used to classify features. Another advantage arises from the notion of inheritance; properties of super classes can be inherited by subclasses without explicitly being repeated. Thus, a more compact representation of knowledge can be achieved.

In the following, several design-oriented formfeature taxonomies that have been reported in literature will be examined. Also, process- planningoriented taxonomies have been proposed, e.g. in References 19, 100, and 101 .

Dixon et al, ${ }^{55}$ proposed a design-with-features taxonomy based on static and kinetic features. Static features are primarily structural in their functional intent, whereas kinetic features entail motion or energy transfer to meet their functional intent. As far as we know only the static features have been subclassified into primitives, intersections, addons, macros and whole forms.

Wilson and Pratt ${ }^{102,14}$ presented a taxonomy of features based on the overall shape of features and the assumption that features will be incorporated in solid modeling systems. Wilson and Pratt distinguish explicit and implicit feature taxonomies, which is related to form-feature representation (section 5.1).

In Reference 23 a design-feature class hierarchy has been presented that is claimed to be especially suitable for modeling parts, assemblies and tolerances. Features can be either composite or atomic. Composite features can be subdivided into kinematic features and fixture features. Atomic features can be node features, volumic features, or library features. 
Wingard ${ }^{6}$ proposed to make form feature taxonomies depend on their application because form features could be divided many different ways based on application, shape, family of parts etc. Wingard suggests one division of form features into subclasses: the division between atomic and compound form features. Atomic form features should be subdivided into part form features, modifier form features, and grouping form features. Part form features can be defined independently of any other existing shape, whereas modifier form features cannot be defined independently of any other shape. Grouping form features group a number of entities because they contain engineering significance. Compound form features should be subdivided into pattern form features and complex form features and (possibly) assembly form features.

\subsubsection{Features and Object-orientation}

Objects and classes are central to the objectoriented paradigm. Objects encapsulate pieces of code (methods) and data and communicate messages with other objects. Objects are organized in a hierarchy of classes. Sub-classes inherit properties from their parent classes.

Features can be regarded as design-objects, belonging to some general class, inheriting properties from their parent classes. Feature taxonomies, as discussed in section 4.3.1, provide for such a feature-class hierarchy. A form-feature model consists of the form-feature class definition and the form-feature instance model. The classes are defined first, as a library from which instances can be created. The class-models do not change often, whereas the instance models are manipulated frequently.

In Reference 103 the use of the object oriented approach in general in CAD has been discussed. See Reference 104 for an object-oriented approach towards feature-based design and Reference 68 for object-oriented assembly and assembly-design process-modeling using features. In Reference 105, the conceptual design of a generic object-oriented tool kit for feature-modeling has been presented. In Reference 7, object-orientation is used for CAD/ CAPP/CAM integration. Almost all references on feature-based design implementation report on using object-oriented software; examples are References $6,23,73$, and 81 .
The object-oriented paradigm has not only been advocated, it has also been criticized; e.g., see Reference 106. One of the current problems in object-oriented programming is the multiple-view problem: objects can be viewed from different viewpoints. This seems to be in accordance with the problem of having multiple views on features (e.g., the design viewpoint and the process-planning viewpoint; section 5.4). The notion of 'role' has been proposed to solve the multiple-view problem in object-oriented programming research, e.g., in Reference 107. However, here one assumes that one knows the different 'roles' (views) beforehand. This is not the case when having multiple viewpoints towards a feature-based model; e.g., the processplanning features model view is not known in advance, but should be inferred from the designfeature model.

\section{Research Issues}

In the following, some particular problems/ research issues related to feature-based design will be discussed. Only research issues in which some progress has been made will be reviewed. The main problems attached to the a priori approach such as function representation, design process models etc. are still open research areas of which some of the first attempts have been reviewed in the preceding sections. Research issues related to the a priori approach will therefore not be discussed. The research problems that will be discussed here are: feature representations (section 5.1), features and constraints (section 5.2), feature validation (section 5..3), multiple views on features (section 5.4), features and standardization (section 5.5) and features and languages (section 5.6). Most of the topics addressed in this chapter are summarized in Table $I$.

\subsection{Feature Representations}

Design-object representation has been addressed in the previous chapter. As features are part of components that constitute the design-object, features should be represented as well. We will focus here on form-feature representation. When considering form-feature representations one should consider the representation of both form and engineering meaning (when adopting the definition of a form feature according to Wingard ${ }^{\mathbf{6}}$ ). 


\section{Form Representation}

No common agreement on the shape representation of form-features has been reached yet. Presently, most researchers seem to agree on a volume representation (sometimes in combination with a surface representation) for form-features. There are advocates of CSG-based representations, e.g., see Reference 73, and of B-rep-based representations, e.g., see References 6, 108, and 109, as well as hybrid representations, e.g., see References 79,81 , 110 , and 111. Recently, also, non-manifold feature representations have been proposed, e.g., see Reference 112. Apart from the geometric representation, features can be represented in many ways: e.g., using attributes and rules; ${ }^{\mathbf{1 0 4 , 1 0 8}}$ diverse forms of graphs;113,114 attributes; ${ }^{55}$ and graph grammars. ${ }^{115}$ For an overview, refer to Table $I$.

In Reference 102, two different approaches towards feature-shape representation have been identified, referred to as implicit and explicit. In the explicit representation, all geometric details of the feature are fully defined. In the implicit representation, sufficient information is supplied to define the feature, but the full geometric details have to be calculated when required. A cylindrical blind hole, for example, may be defined implicitly in terms of its radius and depth, or explicitly in terms of the set of faces that compose it in a boundary representation model. Each type of representation has advantages in different situations. A general purpose system appears, therefore, to benefit from the use of feature-representations having a hybrid nature. Such representations may be achieved by storing two versions of each feature description. ${ }^{110}$ Wingard also concluded that, presently, most people favour a form-feature-based modelling system using a hybrid CSG/B-rep solid modeler. ${ }^{6}$

\section{Engineering Meaning Representation}

Methods for representing engineering meaning are not well developed. Aspects of engineering meaning have so far been described by rules. In the

Table I

Overview: Research in Feature Based-Design: a Posteriori Approaches for Form-Feature-Based Single Component Design

\begin{tabular}{|c|c|c|c|c|c|c|c|c|c|c|}
\hline $\begin{array}{l}\text { Researcher } \\
\text { University } \\
\text { Reference }\end{array}$ & $\begin{array}{l}\text { System } \\
\text { name } \\
\text { (if any) }\end{array}$ & $\begin{array}{l}\text { Form fea- } \\
\text { ture geome- } \\
\text { try repre- } \\
\text { sentation }\end{array}$ & $\begin{array}{l}\text { Feature re- } \\
\text { presentation }\end{array}$ & $\begin{array}{l}\text { Feature re- } \\
\text { lations with- } \\
\text { in compo- } \\
\text { nents }\end{array}$ & $\begin{array}{l}\text { Dimension- } \\
\text { ing \& Toler- } \\
\text { ancing }\end{array}$ & $\begin{array}{l}\text { Feature vali- } \\
\text { dation }\end{array}$ & $\begin{array}{l}\text { Multiple } \\
\text { view hand]- } \\
\text { ing }\end{array}$ & $\begin{array}{l}\text { Applica- } \\
\text { tions follow- } \\
\text { ing FBD }\end{array}$ & \begin{tabular}{|l|} 
Imbedding \\
of (commer- \\
cial) soft- \\
ware
\end{tabular} & $\begin{array}{l}\text { Program- } \\
\text { ming lan- } \\
\text { guage used }\end{array}$ \\
\hline $\begin{array}{l}\text { D.C. Anderson } \\
\text { et al Purctue } \\
\text { University. USA. } \\
\text { [104] [108]. }\end{array}$ & $\begin{array}{l}\text { QTC (Ovick Tur- } \\
\text { neround Cell) }\end{array}$ & CSG/B-rep & $\begin{array}{l}\text { objects: } \\
\text {-attributes } \\
\text {-methods }\end{array}$ & $\begin{array}{l}\text { are inferred from } \\
\text { tays: compound } \\
\text { and pattern feat } \\
\text { tures present }\end{array}$ & $\begin{array}{l}\text { dimensional hot } \\
\text { erances are sup- } \\
\text { ported }\end{array}$ & $\begin{array}{l}\text { can be done as } \\
\text { boundary taces } \\
\text { of feanures are } \\
\text { lageod }\end{array}$ & $\begin{array}{l}\text { by feature refinc- } \\
\text { ment }\end{array}$ & $\begin{array}{l}\text { process planning } \\
\text { inspection }\end{array}$ & $\begin{array}{l}\text { TWIN solid m. } \\
\text { X-windows } \\
\text { KEE expert sys- } \\
\text { tem }\end{array}$ & $\begin{array}{l}\text { Common Lisp } \\
\text { C }\end{array}$ \\
\hline $\begin{array}{l}\text { M.R. Cutkosky } \\
\text { et al Stanfond } \\
\text { University. USA } \\
\text { [86] }\end{array}$ & First-Cut & NURBS & $\begin{array}{l}\text { Objects (frames) } \\
\text {-sttributes } \\
\text {-constraints }\end{array}$ & $?$ & $\begin{array}{l}\text { dimensions are } \\
\text { represented by } \\
\text { constraints }\end{array}$ & $?$ & $\begin{array}{l}\text { by feature reong- } \\
\text { nition: features } \\
\text { alone are not suf- } \\
\text { ficient however. }\end{array}$ & process planning & \begin{tabular}{l|} 
ALPHA-1 \\
NURBS besed \\
solid modeler)
\end{tabular} & $\begin{array}{l}\text { Hypenclass } \\
\text { Lucid Common } \\
\text { Lisp }\end{array}$ \\
\hline $\begin{array}{l}\text { J.R. Diron et al } \\
\text { Umaas Amherst } \\
\text { [S5]. [57], [85]. }\end{array}$ & $\begin{array}{l}\text { several systems } \\
\text { for designing } \\
\text { specific products } \\
\text { (castings injec- } \\
\text { tion molds ete) }\end{array}$ & $\begin{array}{l}\text { datastructure } \\
\text { with } \mathrm{CSG} / \mathrm{B} \text {-rep } \\
\text { like represents- } \\
\text { tion }\end{array}$ & $\begin{array}{l}\text { objects (frames) } \\
\text {-attribures } \\
\text { - constraints }\end{array}$ & $\begin{array}{l}\text { relation graphs } \\
\text { primary and } \\
\text { add-on features } \\
\text { and compound } \\
\text { feanures }\end{array}$ & $\begin{array}{l}\text { only dimension- } \\
\text { ins }\end{array}$ & $?$ & $\begin{array}{l}\text { by feature con- } \\
\text { version [136] }\end{array}$ & analysis & $\begin{array}{l}\text { Geomod solid } \\
\text { modeler }\end{array}$ & Common Lisp \\
\hline $\begin{array}{l}\text { M. van Emmerik } \\
\text { TU Delf NL } \\
{[73] \text {. [130]. }}\end{array}$ & GEONODE & CSG (halispaces) & $\begin{array}{l}\text { objects: } \\
\text {-attribules } \\
\text {-methods }\end{array}$ & $\begin{array}{l}\begin{array}{l}\text { nodes } \\
\text { coordinate } \\
\text { lems) }\end{array} \\
\text { sys- }\end{array}$ & $\begin{array}{l}\text { only dimensions } \\
\text { and dimensional } \\
\text { constraints }\end{array}$ & $\begin{array}{l}\text { by nukes within } \\
\text { objects }\end{array}$ & - & $\begin{array}{l}\text { kinematic analy- } \\
\text { sis }\end{array}$ & $\bar{x} 11$ & $\mathrm{C}++$ \\
\hline $\begin{array}{l}\text { M. Mảntylā et al } \\
\text { Helsints Univ, of } \\
\text { Technology Fin- } \\
\text { land [71]. [134] }\end{array}$ & HUTTPD & CSG/B-sep (?) & $\begin{array}{l}\text { objects (frames) } \\
\text {-attributes } \\
\text {-methods }\end{array}$ & $\begin{array}{l}\text { by onstruction } \\
\text { geometry }\end{array}$ & - & - & $\begin{array}{l}\text { by feature relax- } \\
\text { ation }\end{array}$ & process planning & $\begin{array}{l}\text { GWB solid m. } \\
\text { (acsdemic) } \\
\text { HUTWDN- } \\
\text { DOWS (aca- } \\
\text { demic) }\end{array}$ & Lisp \\
\hline $\begin{array}{l}\text { T. Orsoy et al } \\
\text { Lehigh Univ. } \\
\text { USA [81]. [120] }\end{array}$ & $?$ & CSG/B-rep & objects & $\begin{array}{l}\text { relation graph } \\
\text { primary and sub } \\
\text { features }\end{array}$ & $\begin{array}{l}\text { D\&T present: } \\
\text { using form. prim- } \\
\text { jtive features and } \\
\text { constraints }\end{array}$ & $\begin{array}{l}\text { present: on fea- } \\
\text { ture parameters } \\
\text { and constrainss }\end{array}$ & - & $\begin{array}{l}\text { tolerance snaly- } \\
\text { sis }\end{array}$ & $?$ & $?$ \\
\hline $\begin{array}{l}\text { M.J. Pratt et al } \\
\text { Cranfield Inst } \\
\text { Tech.UK. [110] }\end{array}$ & $?$ & $\begin{array}{l}\text { CSG/B-rep } \\
\text { (non manifold) }\end{array}$ & $\begin{array}{l}\text { implicitexplicit } \\
\text { objects }\end{array}$ & $?$ & $?$ & $?$ & $?$ & $?$ & $\begin{array}{l}\text { Romuhus solid } \\
\text { modeker }\end{array}$ & $?$ \\
\hline $\begin{array}{l}\text { A. Roquicha et al } \\
\text { U. of South Calif } \\
\text { [136]. }\end{array}$ & \begin{tabular}{l|} 
AlSM testbed \\
(Artificial Intelli- \\
gence Solid \\
Modeling)
\end{tabular} & CSG & $\begin{array}{l}\text { objects } \\
\text { - attributes } \\
\text { - methods }\end{array}$ & CSG tree & 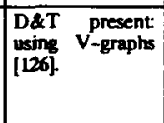 & $\begin{array}{l}\text { by rukes: pres- } \\
\text { ence r.. non-in- } \\
\text { trusion r.. acces- } \\
\text { sibitity i and di- } \\
\text { mensional r. }\end{array}$ & $\begin{array}{l}\text { by feature recog- } \\
\text { nition }\end{array}$ & manufacturing & $\begin{array}{l}\text { PADL-2 solid m. } \\
\text { Knowledgecraft }\end{array}$ & Common Lisp \\
\hline $\begin{array}{l}\text { J.J Shah et al. } \\
\text { Arizona State } \\
\text { Univ.. USA } \\
\text { a.o. [m]. }\end{array}$ & $\begin{array}{l}\text { ASU Features } \\
\text { Testbed }\end{array}$ & CSG/B-rep & $\begin{array}{l}\text { objects } \\
\text { - attributes } \\
\text {-methods }\end{array}$ & $\begin{array}{l}\text { relation graph } \\
\text { primary. sccond- } \\
\text { ay features }\end{array}$ & $\begin{array}{l}\text { D\&T present: } \\
\text { based on }\{118\} \text {. }\end{array}$ & by rules & $\begin{array}{l}\text { by feature map- } \\
\text { ping [131]. }\end{array}$ & $\begin{array}{l}\text { Group Technot } \\
\text { ogy coding man- } \\
\text { uf evaluation. } \\
\text { process planning }\end{array}$ & $\begin{array}{l}\text { Solidesign mod- } \\
\text { eler and several } \\
\text { others }\end{array}$ & C \\
\hline
\end{tabular}


object-oriented approach, engineering meaning can be captured by rules and methods attached to each class description. ${ }^{6}$ A first approach for capturing engineering meaning or design intent has been described in Reference 116, in which geometric relations between features are used for capturing geometric design intent.

\subsection{Features and Constraints (Dimensions and Tolerances)}

In the following, we will consider only dimensioning and tolerancing constraints. In many references, constraints are regarded from a much wider perspective, considering also constraints on weight, kinematics etc.; e.g., see Reference 117.

Solid modeling is an unambiguous way to define a nominal part. However, more information is necessary to complete the variational model, a model representing all allowable variations for the part. Five sorts of these variations or tolerances exist: size, form, orientation, runout, and location. These five sorts of tolerances can be related with primitive features and, in some cases, with formfeatures. Datums are central to dimensioning and tolerancing. Therefore, datum features such as datum planes, datum axes and datum points should also be provided for.

Dimensioning and tolerancing for design drawings are well established via standards: ANSI Y14.5 $M$ for example. Presently, the support of tolerancing in product modelers is an academic research issue as most current CAD systems do not yet support tolerancing.

Dimensions represent geometric constraints. Tolerances are imposed by the function(s) of the parts to be designed and thus represent functional constraints. Therefore tolerancing cannot be dissociated from a matching assembly model. ${ }^{118}$ Tolerancing for function should therefore be an issue of importance. ${ }^{119}$ Tolerance analysis could be possible after tolerancing for function has been done. First attempts on this are reported in References 24 and 120.

Some of the first references on representing tolerances in solid modeling are References 121 and 122. In References 118 and 123 good reviews on supporting tolerances in product modelers are given. Shah ${ }^{118}$ determines 4 kinds of representa- tional models: evaluated entity structure (e.g., see References 124-125); CSG-based structures (e.g., see Reference 126); variational constructive geometry (e.g., see Reference 127); and constraint-based face graphs (e.g. see References 81, 112, and 128).

\subsection{Feature Validation}

Feature interactions cause problems in specifying and validating them in feature-based design; e.g., see References 129,4 , and 130 . They also cause problems in feature recognition. According to Husbands et al, distinction should be made between explicit and implicit feature interactions. ${ }^{4}$ Some feature interactions may be stated explicitly by the designer, e.g. geometric tolerances, but others such as proximity or obstruction may be detected and this is not easy since it is difficult to give a universal definition to such implicit interactions. Therefore, Husbands et al, recommend future research in the area of implicit feature-interaction-recognition as distinct from feature recognition. Husbands et al, propose a test piece for feature-based design systems and feature-recognition systems to test them on the issue of representing/recognizing and validating implicit feature relations.

Van Emmerik proposes to do feature evaluation by means of rule-based systems or by a more interactive approach based on local procedures within the objects to solve ad hoc conflicts. ${ }^{\mathbf{1 3 0}}$ Feature validation seems to be a difficult problem to handle in the most general sense. It is the authors' belief that advantage should be made of the application-dependency of features when trying to handle feature interactions.

\subsection{Multiple Views on Features}

Depending on the application domain, one could have different views towards the same (combination of) form-feature(s) on one component. Each application has its own specific form-features. It is desirable, therefore, to transform from one application model to another. Usually, one would like to transform from a design form-feature model to other form-feature models such as analysis and manufacturing form-feature models. Overcoming these differences in views towards the same component is a non-trivial problem and has been referred to as the 
multiple-view problem. Several solutions to the multiple-view problem have been reported in literature. 108,131-136

In this paper we will focus primarily on the problem of different views towards features between design and process-planning disciplines. The solutions to this problem that have been published until now, have the limitation that-like the early feature-based design approaches-they are focused on single components. Thus, the multipleview problem is solved only at the component level. In practice however, several components might be transformed into one or vice versa when new design requirements give rise to other manufacturing alternatives. Thus, it might be desirable to also take assembly relations into account when trying to overcome the multiple-view problem.

The names attached to the solutions that have been proposed to solve the multiple-view problem usually differ depending on the techniques that have been used. Solutions that have been reported so far are called feature refinement, ${ }^{108}$ feature conversion, ${ }^{55}$ feature mapping, ${ }^{131}$ feature translation, ${ }^{\mathbf{1 3 3}, 135}$ feature transformation, ${ }^{\mathbf{1 1 5}, 132}$ and feature relaxation. ${ }^{\mathbf{1 3 4}}$ In the following, most of the above-mentioned techniques will be explored in some more detail.

\section{Feature Refinement}

Anderson et al, ${ }^{108}$ claim to have found a balance between design and process planning in their Quick Turnaround Cell (QTC) system using so-called feature refinement. Feature refinement maps design features into manufacturing features through geometric reasoning tasks that refine, merge and classify features into an appropriate sequence of machinable activities. However, in this approach a designer has a fixed number of design features that are relatively generic abstractions of manufacturing processes.

\section{Feature Conversion}

Dixon ${ }^{55}$ proposed a design-with-features architecture in which features can be converted from a primary representation to secondary, application dependent representations. Conversion modules do this job. In Reference 136 this conversion process is detailed. The conversion process is subdivided into filtration, selection and aggregation processes. Fil- tration means that only that information needed by the secondary viewpoint is extracted from the primary representation. Selection means applying appropriate conditions. Aggregation means the combination of information into secondary features.

\section{Feature Mapping}

A generic mapping shell has been developed as part of the ASU Features Testbed based on a general theory on feature transformations between application-specific feature-spaces. ${ }^{137}$ The shell can be customized to support the extraction, mapping and reasoning requirements of engineering applications. ${ }^{\mathbf{1 3 1}}$ Functions have been provided for extracting information from the product model if and when needed by the application. The mapping shell also provides an inference engine, a framebased decision tree, and an interpretive language to make the system data-driven. In References 138 and 131 this feature-mapping-and-application shell has been described. In Reference 139 the ASU featuremapping shell has been used for group technology classification. In Reference 140 the featuremapping shell is used to exchange product model data between the ASU Features Testbed and the STEP form-feature information model. Dong et al, ${ }^{\mathbf{1 4 1}}$ reported another kind of feature-mapping: mapping from design-features to manufacturing features for fixture design. The mapping as implemented by Dong et al, seems less mature than the mapping shell by Shah et al, because it seems to take into account only model-independent featuremappings.

\section{Translation to and Recognition from a Geomet- ric Model}

Hummel and Brown, ${ }^{133}$ as well as Requicha and Vandenbrande ${ }^{135}$ advocate the belief that direct translation between design and manufacturing features may be very difficult because several design features (or portions thereof) may contribute to a single manufacturing feature and vice versa. Hummel and Brown expressed stronger belief in translation to and (feature) recognition from a geometric model. This approach is also supported in Reference 7. In Reference 142 this idea has been used for recognizing grasping and assembly features from a feature design model that was converted into B-rep 
form. In Reference 143, inspection features are recognized from a feature model for inspection planning.

In Reference 135, design can be done by using both design features and traditional solid modeling methods. These representations are translated into standard CSG solid representations. These representations are converted into manufacturing formfeatures by a feature-recognizer. This recognizer also uses the design form-feature model, tolerances, feature attributes, etc.

In Reference 113, it is proposed to use graph grammars as an underlying shared representation of both the design and the features. Different applications can then recognize their features by parsing the feature graph against the graph of the object.

\section{Transformation Using Geometric Reasoning}

Reasoning from a (feature-based) design model to an analysis model (consisting of analysis features) is usually the topic of research on features in engineering analysis. In Reference 132, for example, an implementation of a system using geometric reasoning for mapping a design model (formfeatures) into a FEM model (analysis features) has been presented. Feature transformation using geometric reasoning based on a feature graph-grammar in which constraints can be captured is proposed in Reference 115.

\section{Feature Relaxation}

Even within process planning, multiple views can exist towards a part to be manufactured. Mäntylä et al, ${ }^{\mathbf{1 3 4}}$ proposed feature relaxation to solve this problem. In this approach, features can be reinterpreted by the process planner to take into account manufacturing possibilities from a wider range than what one particular selection would make possible.

\subsection{Features and Standardization}

Feature standardization research has been initiated by CAM-I and the US Air Force. CAM-I has been working on the classification of form features for process planning. ${ }^{100}$ The US Air Force has been involved in the PDDI project, which has been concerned with the representation of form-features.
Also, the US Department of Energy reports on a Product Definition Initiative (PDI) project in which a Form Features Centered Architecture (FFCA) is proposed. ${ }^{144}$

Later, within PDES/STEP and ESPRIT (CAD*I), one has worked to develop a Form-Feature Integration Model (FFIM), ${ }^{\mathbf{1 4 5}}$ and a Neutral File Format respectively. FFIM is meant for defining the two lowest data levels of the STEP model representation, i.e., the physical and logical levels. At the logical level, the Express language has been developed to define features and constraints.

In Reference 140, the exchange of product model data (feature models) was experimentally investigated. The exchange of data between the ASU Features Testbed modeler and the STEP FFIM was investigated to identify problems in the FFIM. In Reference 146, differences between FFIM and the Features Constraint model, developed at the University of Minnesota, USA, were reported. It has been stressed by many researchers that standardization should not restrict research in features too much. ${ }^{140}$

\subsection{Features and Languages}

A lot of references have stressed the need for a feature-definition language e.g., see References 5 and 128; design grammars (Research in Engineering Design, Vol.2, 1991); feature grammars; ${ }^{112}$ or languages for functional modeling. ${ }^{\mathbf{4 9}}$ In all these cases, features are central elements in the grammars/ languages. In the approach by Johnson, function is described using verbs, and objects are described using nouns. Objects (nouns) can be assemblies, sub-assemblies, components, or features. ${ }^{49,50}$

Examples of languages that have been reported so far are the Express (section 5.5), ADDL, FDL, and PDGL languages.

ADDL stands for Artifact and Design Description Language, which is used in the IIICAD system. ${ }^{\mathbf{9 4 , 1 4 7}}$ However, only few details on ADDL have been published so far. IDDL is the Japanese version of ADDL. ${ }^{25,54}$

FDL is a functional description language for mechanical design. ${ }^{148} \mathrm{FDL}$ is a language that uses English-like syntax to describe the hierarchical structure and functional relationships of the elements in a mechanical design. 
PDGL stands for Part Design Graph Language. ${ }^{149}$ PDGL is used to describe features in an objectoriented manner, including their technical semantics. The syntax of PDGL is based on Express (see section 5.5). PDGL, in fact, also enables featuremapping by different applications.

\section{Academic Feature-Based Design Systems}

Although some recent commercial CAD systems and tools/kernels have some interesting properties (e.g., ICAD from ICAD Inc.; ${ }^{\mathbf{1 5 0}}$ Concept Modeler from Wisdom Systems Inc.; Pro/Engineer from Parametric Inc.; I-DEAS from SDRC), most advances in CAD systems have come from the academic community. Therefore, in the following, some academic systems that, among others, use features in assisting designers are reviewed. The first system to be reviewed is the ASU Features Testbed; which is probably one of the maturest $a$ posteriori systems (section 6.1). The other systems to be discussed, GEKO/KALEIT, DICAD and III$\mathrm{CAD}$, are a priori systems and are much less mature; these systems will be summarized in section 6.2 .

\subsection{ASU Features Testbed; an a Posteriori System}

The ASU Features Testbed is a collection of modules for the design, documentation, and evaluation of mechanical parts developed at the Arizona State University (ASU) under the supervision of Professor J.J. Shah. In our classification, the ASU Features Testbed is a system of the a posteriori approach; it is used only in the late, detailed design phases for modeling single components. Designing assemblies in a bottom-up fashion has become possible within the ASU Features Testbed only recently. Although only a pre-study on its assemblymodeling capability has been published so far, ${ }^{151}$ we expect a more elaborate publication on this soon. The Testbed is organized into two shells; one for design, and one for mapping and applications. In Reference 5 and 77, a total overview of the ASU Features Testbed is presented. A lot of other papers were published on the ASU features testbed: see References 5, 22, 79, 80, 93, 118, 137, 138, 139, 152 , and 153. In the following, some of them are summarized for each shell.

\section{Design Shell of the ASU Features Testbed}

In Reference 152, the functional requirements and conceptual design of the ASU Features Testbed are given. According to Reference 152, a featuremodelling system should allow the following options: feature creation, feature addition, feature deletion, feature modification; it should support patterns of features and compound features. A limitation of the option of feature-creation is the risk of feature explosion. In Reference 79, material and precision features are introduced; these features can be attached to the part's form-features to capture material, tolerance, and geometry information in one model. Rules, knowledge or constraints can be attached to features to capture product model design knowledge. In Reference 153, design and implementation of the feature-based modeling shell is described.

Within the design shell, there are possibilities for feature-based design, automatic feature recognition and interactive feature definition. ${ }^{8}$ Within the design shell it is also possible to define tolerances on the model. ${ }^{\mathbf{8 0 , 1 1 8}}$ Tolerances that are supported within the ASU testbed modeler can be userdefinable. ANSI Y14.5 tolerance standards are supported. A limitation of the design shell has been reported by Wang et al: ${ }^{\mathbf{8 1}}$ The dimensional relations between form-features are defined by space vectors ( $x, y, z$, alpha, beta, gamma), which-according to Wang et $\mathrm{al}-$ is neither engineering-oriented nor user-friendly. A prototype system that overcomes this problem has been described. ${ }^{81}$

\section{Mapping Shell of the ASU Features Testbed}

In References 131, 137, 138, and 139, the mapping shell has been described. The mapping and application shell maps the model, which is described in terms of design form-features to an application form-feature model. ${ }^{153}$ Applications that have been reported so far are group technology coding, ${ }^{131,139}$ process planning, and manufacturability evaluation, ${ }^{93}$ and mapping to the STEP FFIM. $^{140}$

\subsection{GEKO/KALEIT, DICAD and IIICAD; $a$ Priori Systems \\ GEKO (GEstaltung von KOnstruktionselementen) is a mechanical engineering design support system}


developed at the Technical University of Berlin under Professor W. Beitz. GEKO supports an integrated product model. GEKO is a module of another system, KALEIT, which is aimed to support the entire design process. GEKO is supposed to support the design process in the embodiment and detailed design phases according to the prescriptive VDI 2221 guidelines. ${ }^{32}$ The principle solution model (requirements, function structure, working principle) is GEKO's input. ${ }^{\text {33-37 }}$ The working principle is subdivided into modules (components), and functions are assigned to these modules. GEKO is based on the CATIA solid modeler. Features are used in the modeling functions of GEKO. Distinction is made between calculation-features (auslegungsfeatures) and form-features (gestaltfeatures).

DICAD stands for Dialog-oriented Intelligent CAD system. DICAD is being developed at the University of Karlsruhe under the supervision of Professor H. Grabowski. Central in the concept of DICAD is the so-called integrated product model in which functional, structural and geometric information are integrated. ${ }^{\mathbf{5 3}}$ Function-modeling within DICAD is done according to the classic theory by Roth. ${ }^{46}$ In our feature-based modeling classification, the part of DICAD as developed by Benz, ${ }^{\mathbf{4 6}}$ does not even fall in the category of the a priori approach as the focus is on the functions as such, and not on the components or features.

IIICAD stands for Intelligent, Integrated Interactive CAD system. IIICAD is under development at the Centre for Mathematics and Computer science (CWI) in Amsterdam. The design theory by Yoshikawa, ${ }^{154-155}$ forms the starting point for IIICAD. The central concept behind IIICAD is the separation between object knowledge and process knowledge. A metamodel is used within IIICAD. A metamodel is a central design model from which application models can be inferred. Like DICAD, IIICAD is beyond the category of a priori systems. Recent references on IIICAD are References 94 and 147. The architecture of IIICAD consists of a mechanism for describing the metamodel, a mechanism for describing design process knowledge, a mechanism for translating metamodels into application models, a mechanism for evaluating designs, and a supervisor that controls the problem-solving process. IIICAD employs the ADDL language (Artifact Design Description Language) for describing design knowledge and guaranteeing consistency of the data description. Sometimes this language is referred to as Integrated Design Description Language (IDDL), which now seems to be the Japanese version of ADDL. ${ }^{156,54}$ Until now, no detailed comments on the complexity of the metamodel, the design process model, and the supervisor were given. Also, the way in which application models are obtained from the metamodel is not explained.

\section{Conclusion}

Research is now starting to computer assist more phases of the design process than just part of the detailed design phase. The a priori approach towards feature-based design - as indicated in this paper-seems to be able to play a significant role in this research. In future research efforts, other research in engineering design may become of more importance to feature-based design research. The trend is that features originally closely related to documentation of geometric form can also be used in supporting the design process by: decision support (allowing table look up, standards and calculations); by allowing incomplete geometry in initial design phases that can be enriched gradually later on in the design process; and by capturing functional relations. Also, a better link with applications such as manufacturability evaluation and process planning is anticipated as the "multiple view" problem is now getting a great deal of attention.

Research issues related to feature-based design in the detailed design phase of the design process - the a posteriori approach-have still not been completely solved. These issues are: feature representation, feature validation, features and constraints, multiple views on features, features and languages, features and standardization.

Feature-based design, although still in its infancy, is a fast developing field of research. Features originated from the field of process planning, but have also been used in other application areas such as design, analysis, measuring etc. Feature-based design has not fulfilled its promises yet, as until now it supported only a very small part of the design process. Also, the link between feature-based design and the applications following it has not been fully established. Some interesting 
approaches, however, have already been developed using features for better support of the design process and to integrate design and applications such as manufacturing. It is presently generally believed that such an approach should provide for feature-based design, in combination with feature recognition and interactive feature definition. In future research in feature-based design, research from engineering design in general should also be taken into account.

\section{Acknowledgement}

This research is supported by the Technology Foundation (STW).

\section{References}

1. S. Joshi and T.-C. Chang, "Feature Extraction and Feature Based Design Approaches in the Development of Design Interface for Process Planning," Journal of Intelligent Manufacturing, Vol.1, 1990 , pp. 1-15.

2. J.J. Shah, "An Assessment of Features Technology," CAM-I Report P-90-PM-02, 1990.

3. F.J.A.M. van Houten, "PART: A Computer Aided Process Planning System," PhD Thesis, University of Twente, Enschede, 1991

4. P. Husbands, F. Mill, G. Pedley, and S. Warrington, "The Edinburgh Composite Component," preprints of the MSTF '91, Sth International Conference on Manufacturing Science and Technology of the Future, Enschede, June 1991.

5. Proceedings Features Symposium, CAM-I Report P-90-PM-02, Boston, 1990

6. L. Wingard, "Introducing Form Features in Product Models, A Step Towards CADCAM with Engineering Terminology," Licenciate Thesis, Dept. of Manufacturing Systems, Royal Institute of Technology, Stockholm, 1991

7. M-T. Wang, "An Object-Oriented Feature-Based CADCAPP-CAM Integration Framework," Advances in Design Automa tion, Vol. 1, ASME, 1991, DE Vol. 32-1, pp. 109-116.

8. P.C. Sreevalsan and J.J. Shah, "Unification of Form Feature Definition Methods," IFIP WG5.2, Workshop on Intelligent CAD, Columbus OH, Sept. 1991.

9. L. Alting and H. Zhang, "Computer Aided Process Planning: The State of the Art Survey,' International Journal of Production Research, Vol. 27, No. 4, 1989, pp. 553-85.

10. I. Ham and S.C. Lu, "Computer Aided Process Planning: The Present and the Future," Annals of the CIRP, Vol.37, No.2, 1988, pp. $591-601$

11. J.J. Shah, P. Sreevalsan, and A. Mathew, "Survey of CAD/ Feature Based Process Planning and NC Programming Techniques," Computer Aided Engineering Journal, February 1991, pp. 25-33.

12. J.A. Brimson and P.J. Downey, "Feature Technology: A Key to Manufacturing Integration," CIM Review, Spring 1986, pp. 21-27.

13. M.J. Pratt, "Solid Modeling and the Interface Between Design and Manufacture," IEEE Computer Graphics \& Applications, July 1984, pp. 52-59.

14. M.J. Pratt and P.R. Wilson, "Requirements for Support of Form Features in a Solid Modelling System," final report, CAM-I Report R-85-ASPP-01, June 1985.

15. S.C. Luby, J.R. Dixon, and M.K. Simmons, "Creating and Using a Features Database," Computers in Mechanical Engineering, 1986, pp. 25-33.
16. S. Finger and J.R. Dixon, "A Review of Research in Engineering Design, Part I: Descriptive, Prescriptive and Computer Based Models of Design Processes," Research in Engineering Design, Vol.1, 1989, pp. 51-67

17. S. Finger and J.R. Dixon, "A Review of Research in Mechanical Engineering Design. Part II: Representations, Analysis, and Design for the Lifecycle,"' Research in Engineering Design, Vol. I, 1989, pp. 121-37

18. T.J.A. de Vries, P.C. Breedveld, and J. van Amerongen, "A Design Theory for Classification and Development of CAE Systems,' submitted for presentation at the ASME ' 91 Winter Annual meeting.

19. CAM-I's Illustrated Glossary of Workpiece Form Features, $R-80-P P P-02.1,1981$

20. A.H. van t'Erve, "Computer Aided Process Planning for Part Manufacturing, An Expert System Approach," PhD Thesis, University of Twente, Enschede, 1988.

21 F. Giacometti and T-C. Chang, "A Model for Parts, Assemblies and Tolerances," Preprints of the first IFIP W.G.5.2 Workshop on Design for Manufacturing, Enschede, 1990.

22. J.J. Shah, "Philosophical Development of Form Feature Concept," CAM-I Report P-90-PM-02, 1990.

23. F. Giacometti and T-C. Chang, "Object-Oriented Design for Modelling Parts, Assemblies and Tolerances," Proceedings Technology of Object-Oriented Languages and Systems (TOOLS), Paris, 1990, pp. 243-55.

24. R. Sodhi and J.U. Tumer, "Representing Tolerance and Assembly Information in a Feature Based Design Environment," Advances in Design Automation, DE Vol. 32-1, ASME, 1991, pp. 101-06.

25. T. Kiriyama, T. Tomiyama and H. Yoshikawa, "The Use of Qualitative Physics for Integrated Design Object Modeling," ASME Conference on Design Theory and Methodology, DE Vol. 31, 1991, pp. 53-60.

26. J.J. Shah, "Conceptual Development of Form Features and Feature Modelers," Research in Engineering Design, Vol. 2, 1991 pp. 93-108.

27. E.C. Libardi, J.R. Dixon, and M.K. Simmons, "Computer Environments for the Design of Mechanical Assemblies: A Research Review," Engineering with Computers, Vol. 3, 1988, pp. 121-36.

28. /W.G. Rodenacker, "Methodisches Konstruieren," Springer Verlag, Berlin, Heidelberg, 1970.

29. G. Pahl and W. Beitz, "Konstruktionslehre," Handbuch fur Studium und Praxis, Springer Verlag, Berlin, 1977.

30. R. Koller, "Konstruktionsmethode fur den Maschinen-Gerate und Apparatebau," Springer Verlag, Berlin, Heidelberg, New York, 1979.

31. K. Roth, "Konstruieren mit Konstruktionskatalogen," Systematisierung und zweckmässige Aufbereitung technischen Sachverhalte fur das methodische Konstruieren, Springer Verlag, Berlin, 1982.

32, "VDI, Systematic Approach to the Design of Technical Systems and Products," VDI Guidelines 2221, Beuth Verlag, Berlin, 1987.

33. F. Bauert, "Entwicklung von Werkzeugen zur Produktmodellierung-Bestandteil eines Systemkonzepts zur rechnerunterstützten Gestaltung von Konstruktionselementen (GEKO)," Konstruktion 40, 1988, pp. $90-96$

34. F. Bauert, E. Weise, and N. Salem, "Modellierungsmethoden für Systeme zur rechnerunterstiitzten Gestaltung," Konstruktion 42, 1990, pp. 97-107.

35. F. Bauert, W. Beitz, E. Weise, and N. Salem, "Modeling Methods for a Flexible Computer Aided Embodiment Design System," Research in Engineering Design, Vol. 2, 1990, pp. 15-34.

36. F. Bauert, "Methodische Produktmodellierung für den rechnerunterstützten Entwurf," Schriftenreihe Konstruktionstechnik 18 W. Beitz, PhD Thesis, TU Berlin, 1991.

37. F. Bauert, M. Keller, and T. Simonsohn, "Variations-, Berechnungs und Bewertungsmethoden für die Produktmodellierung mit Beispielen aus dem System GEKO," Konstruktion 43, 1991, pp. $53-60$.

38. D.G. Ullman, T.G. Dietterich, and L. Stauffer, "A Model of the Mechanical Design Process Based on Empirical Data," Artificial Intelligence for Engineering, Design, Analysis and Manufacturing, Vol. 2, No. 1, 1988, pp. 33-52.

39. T.S. Hwang and D.G. Ullman, "The Design Capture System: Capturing Back of the Envelope Sketches," Journal of Engineering Design, Vol. 1, No. 4, 1990. 
40. J.D. Chovan and M.B. Waldron, "Identifying the Fundamental Geometric Attributes of Design: An Application of Distinctive Feature Theory," Proceedings Design Theory and Methodology (DTM) Conference, DE-Vol. 31, ASME, 1991, pp. 209-16.

41. T.A. Kuffner and D.G. Ullman, "The Information Requests of Mechanical Design Engineers," Design Studies, Vol. 12, No. 1, 1991 , pp. 42-50.

42. B.D. McGinnis and D.G. Ullman, "The Evolution of Commitments in the Design of a Component," accepted for publication in the ASME Journal of Mechanical Design for 1991

43. J.J. Shah and P.R. Wilson, "Analysis of Abstraction Representation and Interaction Requirements for Computer Aided Engineering," Computers in Engineering Conference, CIE, San Francisco CA, 1988, pp. 17-24.

44. J. Tikerpuu and D.G. Ullman, "General Feature-Based Frame Representation for Describing Mechanical Engineering Design Developed from Empirical Data," Computers in Engineering Conference (CIE), 1988, pp. 245-53

45. P. Krumhauer, "Rechnerunterstützung für die Konzeptphase der Konstruktion, Ein Beitrag zur Entwicklung eines Programmsystems für die Lösungsfindung Konstruktiver Teilaufgaben," PhD Thesis, Berlin, 1974.

46. T. Benz, "Funktionsmodellieren als Basis für Lösungsfindung in CAD Systermen," PhD Thesis, University of Karlsruhe, 1990.

47. H. Schmekel, A System for Conceptual Design of Parts,“ Licentiate Thesis, Royal Institute of Technology, Stockholm, 1989.

48. H. Schmekel, "Modeling of Conceptual Design Using Axiomatics," Report Royal Institute of Technology, Stockholm, 1990.

49. A.L. Johnson, 'Designing by Functions," Design Studies, Vol. 12 , No. 1 , January 1991 , pp. 51-57.

50. A.L. Johnson and A.C. Thomton, "Towards Real CAD," International Conference on Engineering Design, ICED 91, Zurich, August 27-29, 1991

51. M. von Rimscha, "Feature Modelling and Assembly Modelling-A Unified Approach," Advanced Geometric Modelling for Engineering Applications, edited by F.-L. Krause and H. Jansen, Elsevier, IFIP/GI, 1990, pp. 203-13.

52. M. Mäntylä, Directions for Research in Product Modeling, in Computer Applications in Production Engineering, edited by F. Kimura, A. Rolstadas, Elsevier Science Publishers (North Holland), IFIP, 1989.

53. H. Grabowski, R. Anderl, V. Holland-Letz, B. Patzold, and A. Suhm, "An Integrated CAD/CAM-System for Product and Process Modelling," Advanced Geometric Modelling for Engineering Applications, edited by F.-L. Krause and H. Jansen, Elsevier Science Publishers, 1990

54. T. Kiriyama, K. Kurumatani, T. Tomiyama, and $H$. Yoshikawa, "Qualitative Behavior Representation and Reasoning for Intelligent CAD Systems, " Computer Applications in Production and Engineering, edited by F. Kimura and A. Rolstadas, Elsevier Science Publishers B.V. (North Holland), IFIP, 1989.

55. J.R. Dixon, J.J. Cunningham, and M.K. Simmons, "Research in Designing with Features, in Intelligent CAD, I," edited by $H$. Yoshikawa and D. Gossard, Proceeding IFIP TC 5/WG 5.2 Workshop on Intelligent $C A D$, Elsevier, 1987, pp. 137-48.

56. J.J. Shah, "Synthesis of Initial Form for Structural Shape Optimization," Transactions of the ASME, Vol. 110, 1988, pp. 564-70.

57. M.R. Duffey and J.R. Dixon, "Automating Extrusion Design: A Case Study in Geometric and Topological Reasoning for Mechanical Design," $C A D$, Vol. 20, No. 10, December 1988, pp. 589-96.

58. M.K. Zamaniam, S.J. Fenves, C.R. Thewalt, and S. Finger, "A Feature-Based Approach to Structural Design," Engineering with Computers, Vol. 7, 1991, pp. 1-9.

59. R.V. Welch and J.R. Dixon, "Configuration Design by Iterative Redesign: Sheet Metal Bracket Design as an Example," Journal of Engineering Design, Vol. 1, No. 3, 1990, pp. 221-37.

60. K. Lee and D.C. Gossard, "A Hierarchical Data Structure for Representing Assemblies: Part 1," $C A D$, Vol. 17, No. 1, 1985, pp. 15-19.

61. K. Lee and G. Andrews, "Inference of the Positions of Components in an Assembly: Part 2, " $C A D$, Vol. 17, No. 1, 1985, pp. 20-24.
62. F. Kimura, H. Suzuki, and I. Tanaka, "A Pattern-Directed Design System for Machine Assembly, "Annals of the CIRP, Vol. 40, No. 1, 1991, pp. 127-30.

63. H.L. Johannesson, "Computer Aided Part Design Based on Standard Component Interface Geometry," Proceedings Advances in Design Automation, DE-Vol. 32, No. 2, ASME 1991, pp. 347-52.

64. M. Yoshimura and A. Takeuchi, "Integrated Optimization in Computer-Aided Design and Manufacturing of Machine Products Based on Shape Descriptions of Contact Surfaces, " Advances in Design Automation, ASME, DE-Vol.32-2, 1991, pp. 353-60.

65. E. Molloy, H. Yang, and J. Browne, "Design for Assembly Within Concurrent Engineering," Annals of the CIRP, Vol. 40, No. 1, 1991, pp. 107-10.

66. U. Roy, P. Banerjee, and C.R. Liu, "Design of an Automated Assembly Environment," CAD, Vol. 21, No. 9., 1989, pp. 561-69. 67. H-C. Liu and B.O. Nnaji, 'Design with Spatial Relationships, “ Journal of Manufacturing Systems, Vol. 10, No. 6, 1991, pp. 449-63.

68. J.K. Gui, "Object-Oriented Assembly and Assembly Design Process Modeling,“ Journal of Engineering Design, Vol. 2, No. 2, 1991

69. N. Wang and T.M. Ozsoy, "Representation of Assemblies for Automatic Tolerance Chain Generation," Engineering with Computers, Vol. 6, 1990, pp. 121-26.

70. H. Ko and K. Lee, "Automatic Assembling Procedure Generation from Mating Conditions," $C A D$, Vol. 19, No.1, 1987, pp. 3-10.

71. T. Laako, M. Mäntylä, R. Mäntylä, J. Nieminen, R. Sulonen, and J. Tuomi, "Feature Models for Design and Manufacturing, " $23 r d$ Hawaii International Conference on System Sciences, IEEE, Vol. II, edited by B.D. Shriver, 1990, pp. 445-54

72. J. Nieminen, J. Kanerva, and M. Mäntylä, 'Feature-Based Design of Joints," Advanced Geometric Modelling for Engineering Applications, edited by F-L. Krause and H. Jansen, Elsevier Science Publishers (North Holland), IFIP/GI, 1990.

73. M.J.G.M. van Emmerik, "Interactive Design of Parameterized 3D Models by Direct Manipulation," PhD Thesis, Delft University, The Netherlands, 1990.

74. F. Giacometti and T.-C. Chang, "Design of Mechanical Assemblies with Functional Features," preview paper 1991 Design Automation Conference, Miami, FL, September 23-27, 1991.

75. D. Roller, 'Design by Features: An Approach to High Level Shape Manipulations," Computers in Industry, Vol. 12, 1989, pp. $185-91$.

76. G. Catania, 'Form-Features for Mechanical Design and Manufacturing, " Journal of Engineering Design, Vol. 2, No. 1, 1991, pp. $21-43$.

77. J.J. Shah, M.T. Rogers, P.C. Sreevalsan, D. Hsiao, A. Mathew, A. Bhatnagar, B. Liou, and D.W. Miller, "The ASU Features Testbed: An Overview," ASME Computers in Engineering Conference (CIE), 1990, pp. 233-41.

78. L.S. Wierda, 'Linking Design, Process Planning and Cost Information by Feature Based Modelling," Journal of Engineering Design, Vol. 2, No. 1, 1991, pp. 3-19.

79. J.J. Shah and M.T. Rogers, "'Expert Form Feature Modelling Shell," Computer Aided Design, Vol. 20, No. 9, 1988, pp. 515-24. 80. J.J. Shah and D. Miller, "A Structure for Integrating Geometric Tolerances with Form Features and Geometric Models, "Computers in Engineering (CIE), 1989, pp. 395-402.

81. N. Wang and T.M. Ozsoy, "A Scheme to Represent Features, Dimensions and Tolerances in Geometric Modeling," Journal of Manufacturing Systems, Vol. 10, No. 3, 1991, pp. 233-40.

82. J.C.H. Chung and R.L. Cook, "Feature-Based Geometry Construction for Geometric Reasoning, " initial draft for the ASME 1988 Computers in Engineering Conference (CIE), 1987.

83. S.C. Luby, J.R. Dixon, and M.K. Simmons, 'Designing with Features: Creating and Using a Features Database for Evaluation of Manufacturability of Castings," ASME Computers in Engineering Conference (CIE), 1986, pp. 285-92.

84. R.K. Irani, B.H. Kim, and J.R. Dixon, 'Integrating CAE, Features and Iterative Design of Injection Molds," ASME Computers in Engineering Conference CIE '89, Vol. 1, Anaheim CA, edited by D.R. Riley and T.J. Cokonis, 1989, pp. 27-33.

85. J.J. Cunningham and J.R. Dixon, 'Designing with Features: The Origin of Features, " Computers in Engineering Conference, CIE, San Francisco CA, 1988, pp. 237-43. 
86. M.R. Cutkosky, J.M. Tenenbaum, and D. Muller, 'Features in Process Based Design," ASME Computers in Engineering (CIE) Conference, San Francisco CA, 1988, pp. 557-62.

87. H.W. Stoll, "Design for Manufacture," Manufacturing Engineering, January $1988,67-73$.

88. G. Boothroyd, "Making it Simple, Design for Assembly," Mechanical Engineering, February 1988, pp. 28-30.

89. S. Subramaniam and S.C. Lu, "The Impact of an AI Based Design Environment for Simultaneous Engineering on Process Planning," International Journal of Computers In Manufacturing, Vol. 4, No. 2, 1991, pp. 71-82.

90. M. Ranta, M. Inui, and F. Kimura, "A Process Planning System for Producibility Feedback to Designers," Computer Applications in Production and Engineering, edited by F. Kimura and A. Rolstadas, Elsevier Science Publishers B.V., IFIP, 1989.

91. M. Azari, "Product Model and Integrated System for Design for Assembly and Parts Manufacture, A Case of Study," Internal Report, RIT, Stockholm, 1990.

92. N.J. Yannoulakis, S.B. Joshi, and R.A. Wysk, "A Manufacturability Evaluation System," Design Theory and Methodology Conference, DE-Vol. 31, ASME, 1991, pp. 217-26.

93. J.J. Shah, D. Hsiao, and R. Robinson, "A Framework for Manufacturability Evaluation in a Feature Based CAD System," NSF Design \& Manufacturability Research Conference, Tempe, AZ, January 1990, pp. 61-66.

94. P. Veerkamp and P. ten Hagen, 'Qualitative Reasoning About Design Objects," preprints of the MSTF'9I Conference, Enschede, June 1991.

95. P.R. Wilson, "Solid Modeling Research and Applications in the USA, Geometric Modeling for CAD Applications, edited by M.J. Wozny and J.L. McLaughlin, Elsevier Science Publishers B.V. (North Holland), IFIP, 1988, pp. 69-88.

96. H. Masuda, K. Shimada, M. Numao, and S. Kawabe, "A Mathematical Theory and Applications of Non-Manifold Geometric Modeling," Advanced Geometric Modelling for Engineering Applications, edited by F-L. Krause and H. Jansen, Elsevier Science Publishers B.V. (North Holland), IFIP/GI, 1990, pp. 89-103.

97. K. Weiler, "Boundary Graph Operators for Non-Manifold Geometric Modeling Topology Representations," Geometric Modeling for CAD Applications, edited by M.J. Wozny and H.W. McLaughlin, Elsevier Science Publishers B.V. (North Holland), IFIP, 1988, pp. $37-66$.

98. L.T.M. Stomph-Blessing, "Methodisch ontwerpen en kunstmatige intelligentie, een literatuuronderzoek," University of Twente, Faculty Mechanical Engineering, Internal Report No. OC171, in Dutch, Enschede, 1988.

99. L.T.M. Stomph-Blessing, "Engineering Design and Artificial Intelligence: A Promising Marriage?,' Workshop Research in Design Thinking, Faculty of Industrial Design, TU Delft, May 29-31, 1991. 100. "Part Features for Process Planning," CAM-I Report $R$ 86-PPP-01, 1986

101. N.N.Z. Gindy, "A Hierarchical Structure for Form Features," International Journal of Production Research, Vol. 27, No. 12, 1989, pp. 2089-2103.

102. P.R. Wilson and M.J. Pratt, "A Taxonomy of Form Features for Solid Modeling," Geometric Modeling for CAD Applications, edited by M.J. Wozny and H.W. McLaughlin, Elsevier Science Publishers B.V. (North Holland), IFIP, 1988, pp. 125-35.

103. E.A. Warman, "Object Oriented Programming and CAD," Journal of Engineering Design, Vol.1, No.1, 1990.

104. D.C. Anderson and T.C. Chang, "Automated Process Planning Using Object-Oriented Feature Based Design," Advanced Geometric Modelling for Engineering Applications, edited by F.-L. Krause and H. Jansen, Elsevier, IFIP/GI, 1990.

105. P. Sreevalsan, M. Rogers, and J.J. Shah, "Object Oriented Tools for Feature Database Design," ASME Winter Annual Meeting, Dallas, TX, 1990

106. S. Guthery, "Are the Emperor's New Clothes Object Oriented?," Dr. Dobb's Journal, December 1989

107. B. Pernici, "Objects with Roles," Proceeding Conference on Office Information Systems, edited by F.H. Lochovsky and R.B. Allen, Cambridge, MA, 1990, pp. 205-16.

108. D.C. Anderson, T.C. Chang, A. Kak, and O.R. Mitchell, "A Quick Turnaround Cell," CAM-I Report No. P-90-PM-02, 1990.
109. M.J. Pratt, "Synthesis of an Optimal Approach to Form Feature Modelling," ASME Computers in Engineering Conference (CIE), San Francisco CA, 1988, pp. 263-74.

110. M.J. Pratt, "A Hybrid Feature Based Modelling System," Advanced Geometric Modelling for Engineering Applications, edited by F.-L. Krause and H. Jansen, Elsevier Science Publishers B.V. (North Holland), 1990, pp. 189-201.

111. U. Roy, C.R. Liu, "Feature-Based Representational Scheme of a Solid Modeler for Providing Dimensioning and Tolerancing Information," Robotics \& Computer-Integrated Manufacturing, Vol. 4 , No $3 / 4,1988$, pp. 335-45.

112. S. Finger and S.A. Safier, "Representing and Recognizing Features in Mechanical Designs," Second International Conference on Design Theory and Methodology DTM '90, Chicago IL, September 1990.

113. S. Joshi and T.-C. Chang, "Graph-Based Heuristics for Recognition of Machined Features from a 3-D Solid Model," ComputerAided Design, Vol. 20, No.2, 1988, pp. 58-64.

114. R.E. Billo, M. Henderson, and R. Rucker, "Applying Conceptual Graph Inferencing to Feature-Based Engineering Analysis," Computers in Industry, Vol. 13, 1989, pp. 195-214.

115. Z. Fu and A. de Pennington, "Geometric Reasoning Based on Graph Grammar Parsing," Advances in Design Automation, Vol. 2, ASME 1991, pp. 13-22.

116. E.H. Nielsen, J.R. Dixon, and G.E. Zinsmeister, "Capturing and Using Designer Intent in a Design with Features System," Proceedings Design Theory and Methodology, D-E Vol. 31, ASME 1991 , pp. 95-102.

117. F. Kimura and H. Suzuki, "Variational Product Design by Constraint Propagation and Satisfaction in Product Modelling," Annals of the CIRP, Vol. 35, No. 1, 1986, pp. 75-78.

118. J.J. Shah and D.W. Miller, "A Structure for Supporting Geometric Tolerances in Product Definition Systems for CIM,' Manufacturing Review, No. 1, March 1990, pp. 23-31.

119. R. Weill, "Tolerancing for Function," Annals of the CIRP, Vol. 37, No. 2, 1988, pp. 603-10.

120. P. Treacy, J.B. Ochs, T.M. Ozsoy, and N. Wang, "Automated Tolerance Analysis for Mechanical Assemblies Modeled with Geometric Features and Relational Data Structure," $C A D$, Vol. 23, No. 6, 1991, pp. 444-53.

121. R.C. Hillyard and I.C. Braid, "Analysis of Dimensions and Tolerances in Computer-Aided Mechanical Design," CAD, Vol. 10, No.3, 1978, pp. 161-66.

122. A.A.G. Requicha, "Representation of Tolerances in Solid Modeling: Issues and Alternative Approaches," Solid Modeling by Computers, From Theory to Applications, edited by M.S. Picket and J.W. Boyse, Plenum Press, 1984.

123. U. Roy, C.R. Liu, and T.C. Woo, "Review of Dimensioning and Tolerancing: Representation and Processing," $C A D$, Vol. 23, No. $7,1991,466-83$

124. R.H. Johnson, "Dimensioning and Tolerancing," final report, CAM-I, R84-GM-O2-2, Arlington, TX, May 1985.

125. P.S. Ranyak and R. Fridshal, "Features for Tolerancing a Solid Model," Computers in Engineering Conference (CIE), San Francisco CA, 1988, pp. 275-80.

126. A.A.G. Requicha and S.C. Chan, "Representation of Geometric Features, Tolerances and Attributes in Solid Modelers Based on Constructive Geometry," IEEE Journal of Robotics \& Automation, Vol. RA-2, No.3, 1986, pp. 156-66.

127. J.U. Turner and M.J. Wozny, "A Mathematical Theory of Tolerances," Geometric Modelling for CAD Applications, edited by M.J. Wozny and McLaughlin, Elsevier Science Publishers, IFIP, 1988 .

128. I.D. Faux, "Reconciliation of Design and Manufacturing Requirements for Product Description Data Using Functional Primitive Part Features," CAM-I report R-86-ANC/GM/PP-01, 1986 129. J.J. Shah, "Assessment of Features Technology," CAD, Vol 23, No. 5, 1991, pp. 331-43

130. M.J.G.M. van Emmerik and F.W. Jansen, "User Interface for Feature Modelling," Computer Applications in Production and Engineering, edited by F. Kimura and A. Rolstadas, Elsevier, IFTP, 1989. 131. A.S. Bhatnagar, "Implementation of Feature Mapping and Reasoning Shell with Application to Group Technology Coding," MSC Thesis, Arizona State University, August 1988. 
132. K.N. Brown, J.H. Sims Williams, J. Devlukia, and C.A. McMahon, "Reasoning with Geometry; Predicting Stress Concentration Factors," Artificial Intelligence in Engineering, Vol. 5, No. 4, 1990, pp. 182-88

133. K.E. Hummel and C.W. Brown, "The Role of Features in the Implementation of Concurrent Product and Process Design," ASME Winter Meeting, San Francisco CA, 1989, pp. 1-8.

134. M. Mäntylä, J. Opas, and J. Puhakka, "Generative Process Planning of Prismatic Parts by Feature Relaxation," Advances of Design Automation 1989, presented at the ASME Design Technical Conferences-15th Design Automation Conference, Montreal Quebec, Canada, 1989, pp. 49-60

135. A.A.G. Requicha and J.H. Vandenbrande, "Form Features for Mechanical Design and Manufacturing," Proceedings ASME International Computers in Engineering Conference (CIE). Anaheim CA, 1989. pp. 47-52.

136, D.W. Rosen, J.R. Dixon, and X. Dong, "A Methodology for Conversions of Feature Based Representations," International Conference on Design Theory and Methodology DTM '91, ASME, edited by D.E. Stauffer, Vol. 31, 1991, pp. 45-51.

137. J.J. Shah, "Feature Transformations Between ApplicationSpecific Feature Spaces," Computer Aided Engineering Journal, December 1988, pp. 247-55.

138. J.J. Shah, A. Bhatnagar, and D. Hsiao, "Feature Mapping and Application Shell," Computers in Engineering Conference (CIE), San Francisco CA, 1988, pp. 489-96.

139. J.J. Shah and A.S. Bhatnagar, "Group Technology Classification from Feature-Based Geometric Models," Manufacturing Review, Vol. 2, No. 3, September 1989, pp. 204-13.

140. J.J. Shah and A. Mathew, "Experimental Investigation of the STEP Form-Feature Information Model," CAD, Vol. 23, No. 4, 1991, pp. 282-96.

141. X. Dong, W.R. DeVries, and M.J. Wozny, "Feature-Based Reasoning in Fixture Design," Annals of the CIRP, Vol. 40, No. 1, 1991, pp. 111-14.

142. F. Mandorli and I. Vicini, "A Form Features Automatic Recognition System," submitted to ICAR '91, Pisa, Vol. 2022/6/1991.

143. H.A. ElMaraghy and P.H. Gu, "Expert System for Inspection Planning," Annals of the CIRP, Vol. 36, No. 1, 1987, pp. 85-89.

144. D.L. Vickers and K.A. Swanson, "A Form Features Centered Architecture for Product Definition Exchange," Proceeding Autofact '88, Chicago IL, 1988.

145. "PDES, PDES Form Feature Information Model, Version 3 (Working)," edited by M. Dunn, United Technologies Research Center, December 17, 1987 .

146. R.D. Parks and T.R. Chase, "Representing Mechanical Parts Using Feature Specifications and Positional Constraints: A Contrast with PDES," Engineering Database Management: Leadership for the 90's, ASME, 1989, pp. 81-96.

147. V. Akman, P.J.W. ten Hagen and T. Tomiyama, "A Fundamental and Theoretical Framework for an Intelligent CAD System," $C A D$, Vol. 22, No. 6, 1990, pp. 352-67.
148. K. Lai and W.R.D. Wilson, "FDL-Language for Function Description and Rationalization in Mechanical Design," ASME International Computers in Engineering Conference (CIE), New York NY, 1987, pp. 87-94.

149. F.-L. Krause, S. Kramer, and E. Rieger, "PDGL: A Language for Efficient Feature-Based Product Gestaltung," Annals of the CIRP, Vol. 40, No. 1, 1991, pp. 135-38.

150. M.R. Wagner, "Understanding the ICAD System," ICAD Inc., Cambridge MA, 1990.

151. J.J. Shah, "Requirements for Support of Assembly Modeling in a Feature Based Environment," a proposal submitted to CAM-I, August 1989.

152. J.J. Shah and M.T. Rogers, "Functional Requirements and Conceptual Design of the Feature-Based Modelling System," Computer Aided Engineering Journal, February 1988, pp. 9-15.

153. J.J. Shah and M.T. Rogers, "Feature Based Modeling Shell: Design and Implementation," Computers in Engineering Conference (CIE), San Francisco CA, 1988, pp. 255-61.

154. T. Tomiyama and H. Yoshikawa, "Extended General Design Theory," Design Theory for CAD, edited by H. Yoshikawa and E.A. Warman, Elsevier Science Publishers (North Holland), IFIP, 1987.

155. H. Yoshikawa, "Design Theory for CAD/CAM Integration," Annals of the CIRP, Vol. 34, 1985, 173-78.

156. Y. Ishida, D. Xue, S. Hamada, T. Tomiyama, and $H$. Yoshikawa, "A User Interface System for a Design Description Language in Intelligent CAD Systems," Computer Applications in Production and Engineering, edited by F. Kimura and A. Rolstadas, Elsevier Science Publishers (North Holland), IFIP, 1989.

\section{Author Biographies}

O.W. Salomons is a $\mathrm{PhD}$ candidate working at the laboratory of Production Engineering at the University of Twente. Salomons obtained his MS degree in mechanical engineering in 1990 at the University of Twente. Presently he is working in the field of feature based design and its link with CAPP.

F.J.A.M. van Houten is associate professor of the laboratory of Production Engineering at the University of Twente. Van Houten obtained his MS degree in mechanical engineering at the Technical University of Eindhoven in 1976. He has been working at the laboratory of Production Engineering at University of Twente since 1978. Van Houten has worked in the field of CAD and CAPP; he has been closely involved with the development of several CAPP systems. In 1991 he obtained a PhD degree on his work on the PART system.

H.J.J. Kals is professor and head of the laboratory of Production Engineering at the University of Twente. Kals obtained his MS degree in mechanical engineering in 1969 at the Technical University of Eindhoven and his PhD degree in 1972. In 1977 he became professor of the Laboratory of Production Engineering at the University of Twente. Kals is a member of CIRP. He is active in the fields of CAD, CAPP, CAM, workshop- and work station control. Currently one of his main scientific interests is concurrent engineering. 